\title{
Effects of insulin and fetal bovine serum on lipoprotein lipase and glucose and acetate utilizations by cultured bovine adipose tissue explants
}

\author{
Y Faulconnier, M Thévenet, J Fléchet, Y Chilliard
}

\author{
INRA, Laboratoire Sous-Nutrition des Ruminants, Theix, \\ 63122 Saint-Genès-Champanelle, France
}

\begin{abstract}
A system of culture of bovine adipose tissue (AT) explants was used to study the regulation of bovine lipoprotein lipase (LPL). The in vitro utilization of 2 energy and lipogenic substrates (glucose, acetate) was determined. The effect of insulin ( $2 \mathrm{mUl} / \mathrm{ml}$ ) and/or fetal bovine serurn (FBS, $10 \%$ ), which stimulated LPL activity in monogastric AT, were studied. Nine dry non-pregnant Holstein cows were maintained for $10 \mathrm{~d}$ on a restricted diet ( $25 \%$ of energy maintenance requirement, EMR) then overfed (222\% of EMR) for 3-5 weeks before slaughter, in order to increase lipid deposition and lipogenic activities. Samples of perirenal AT were collected, finely cut in 10-15 mg pieces, and cultured in sterile conditions for 24 or $48 \mathrm{~h}$. The LPL activity was measured after a detergent (deoxycholate-nonidet $P_{40}$ ) extraction procedure.
\end{abstract}

The glucose utilization was significantly increased by insulin addition, with or without FBS (table I). It was also enhanced by the addition of FBS alone showing close additive effects of insulin and FBS. The acetate utilization was significantly increased by insulin addition, without additional effect of FBS. The LPL activity declined after 24 or $48 \mathrm{~h}$ of culture. It was significantly increased by insulin, but only in the absence of FBS, which completely abolished the insulin effect (significant negative interaction). The FBS alone had no effect on LPL activity. These data validate the use of bovine AT explants as a model for metabolic studies, and confirm the direct anabolic effect of insulin on ruminant AT.

Table I. Effects of insulin (2 mUl/ml) and fetal bovine serum (FBS, $10 \%$ ) on glucose and acetate utilization and lipoprotein lipase (LPL) activity of cultured bovine adipose tissue (AT) explants.

\begin{tabular}{|c|c|c|c|c|c|c|c|}
\hline & \multirow{2}{*}{ Control } & \multirow{2}{*}{ Insulin } & \multirow{2}{*}{$F B S$} & \multirow{2}{*}{ Insulin + FBS } & \multicolumn{3}{|c|}{ Effects $(P<$} \\
\hline & & & & & 1 & $F B S$ & $I x F B S^{a}$ \\
\hline \multicolumn{8}{|l|}{ Day $1^{b}$} \\
\hline Glucose c & 12.1 & 22.8 & 16.1 & 28.2 & 0.001 & 0.001 & 0.57 \\
\hline Acetate $\mathrm{c}$ & 35.8 & 60.6 & 49.2 & 59.9 & 0.001 & 0.19 & 0.15 \\
\hline LPLd & 48.1 & 59.2 & 49.5 & 47.4 & 0.11 & 0.07 & 0.02 \\
\hline \multicolumn{8}{|l|}{ Day $2^{b}$} \\
\hline Glucosec & 17.3 & 25.5 & 20.2 & 31.0 & 0.001 & 0.03 & 0.44 \\
\hline Acetatec & 30.9 & 59.0 & 38.8 & 52.8 & 0.001 & 0.87 & 0.20 \\
\hline LPLd & 35.1 & 47.3 & 31.9 & 33.0 & 0.01 & 0.001 & 0.02 \\
\hline
\end{tabular}

a I $\times$ FBS = insulin $\times$ FBS interaction; b glucose and acetate utilizations between 0 and $24 \mathrm{~h}$ (day 1) or 24 and $48 \mathrm{~h}$ (day 2), LPL activities after 24 (day 1) or 48 (day 2) $\mathrm{h}$ of culture; ${ }^{c} \mu \mathrm{mol} / \mathrm{g}$ AT per $24 \mathrm{~h}$; d \% of initial activities (133 $\pm 31 \mathrm{nmol}$ fatty acids/min per $\mathrm{g} A T$, at day 0 ). 